\title{
Critical effect of film thickness on preconcentration electroanalysis with oriented mesoporous silica modified electrodes
}

Tauqir NASIR, ${ }^{a}$ Natalya A. VODOLAZKAYA,,${ }^{\mathrm{a}, \mathrm{b}}$ Grégoire HERZOG, ${ }^{\text {,* }}$ Alain WALCARIUS ${ }^{*}$

${ }^{a}$ Laboratoire de Chimie Physique et Microbiologie pour les Matériaux et l'Environnement (LCPME), UMR7564 CNRS - Université de Lorraine, 405 rue de Vandoeuvre, 54600 Villers-les-Nancy, France

${ }^{\mathrm{b}}$ Chemical Faculty, Department of Physical Chemistry, V.N. Karazin Kharkov National University, 61022 Kharkov, Ukraine

* e-mail: alain.walcarius@univ-lorraine.fr, gregoire.herzog@univ-lorraine.fr

\begin{abstract}
Electrogenerated silica thin films exhibiting a regular hexagonal packing of vertically-aligned mesopore channels are promising for preconcentration electroanalysis. This work demonstrates the critical role of film thickness on their sensing performance using paraquat as a model analyte, based on mesoporous silica films prepared by electrochemically assisted self-assembly performed for various deposition times. Films prepared with too short synthesis times $(<10 \mathrm{~s})$ led to deposits covering partially the electrode surface and suffered from rather poor sensing performance. Then, uniformly deposited films were obtained (between 10 and $15 \mathrm{~s}$ ), and sensitivity rose up by increasing deposition times, whereas some limitations started to occur with much thicker films ( $>$ 15 s deposition times) as a result of less electrochemically accessible paraquat accumulated far away from the electrode surface and restricted mass transport through the whole film thickness. These limitations were also confirmed on the basis of multi-layered mesoporous silica films, suggesting a behavior that might be typical for other types of film-modified electrodes.
\end{abstract}

Keywords: Mesoporous silica, Thin film, Voltammetric detection, Paraquat, Sensitivity. 
Thin films made of nanostructured and highly porous metal oxides exhibiting well-ordered mesochannels of monodisperse size are very attractive for applications in many fields, such as dyesensitized solar cells [1], energy storage [2], electrochromism [3], photocatalysis [4], gas sensors [5], or electrochemistry [6]. Ordered mesoporous materials are also of outstanding interest for sensing and biosensing [7]. Periodically organized nanoporous thin films can be obtained via surfactant templated growth of inorganic or hybrid polymers [8], but an important point governing their performance relies on nanoscale control of compositions and mesochannel orientation [9], to ensure the accessibility of mesoporous thin films from surfaces [10]. An effective way to reach this goal is via the vertical orientation of mesopore channels [11]. Nanostructured thin films with vertically aligned mesochannels are very attractive for electroanalysis [12] because this pore configuration enables fast mass transfer processes from the solution to the electrode surface (as easily characterized by electrochemical methods [13]). Such films can be prepared by electroassisted self-assembly (EASA) [11a,14] or by the Stöber solution growth process [11b], which are the two most versatile methods available to date to prepare vertically oriented mesoporous silica films on electrodes giving rise to well-defined electrochemical characteristics [15]. Good adhesion to the support is ensured for films generated as such onto electrode surfaces bearing surface hydroxyl groups, whereas using "molecular glue" is mandatory for other electrode substrates (such as electrografting of 3-aminopropyltriethoxysilane on glassy carbon [16]) prior to film deposition. Electroanalytical interests have been reported for surfactant-containing, template-extracted, organically-functionalized, and free-standing oriented mesoporous silica thin films [12]. Surfactantcontaining films have been used as permselective sensors for lipophilic analytes (e.g., pharmaceutical drugs [17] or trace nitroaromatic explosives and pesticides [18]) based on their extraction/dissolving in the surfactant phase and subsequent detection onto the electrode surface while rejecting ionic interferences [19]. Applications of surfactant-extracted films include preconcentration electroanalysis of redox cations (via electrostatic binding to the negatively charged silica surface) [20,21], permselective coatings (based on charge selectivity [22], hydrophobic/ hydrophilic balance [23] or gated molecular transport [24]), or molecular sieving membranes [25] which are also likely to be exploited as anti-fouling surfaces [26]. Oriented mesoporous silica films bearing organo-functional groups can be also manufactured [27]. They have been exploited in electroanalysis based on preferential accumulation/detection of target species via complexation [28] or electrostatic binding [29], as electrochemical bioassays [30], or as electrocatalytic sensors [31]. Electrochemiluminescence sensors have been also described [32,33]. Finally, free-standing mesoporous silica membranes can be used for molecular filtration [34]. In a previous work [21], we have shown that perpendicularly oriented mesoporous silica thin films electrogenerated by EASA 
on glassy carbon electrode can be successfully applied to the preconcentration electroanalysis of paraquat, a cationic 4,4'-bipyridinium-based pesticide likely to bind quickly to the negatively charged silica surface. Here we discuss the critical effect of film thickness of the sensor's sensitivity, on the basis of deposits obtained after distinct synthesis durations.

Figure 1 shows typical cyclic voltammograms recorded in $0.5 \mathrm{mM} \mathrm{Ru}\left(\mathrm{NH}_{3}\right)_{6}{ }^{3+}$ using glassy carbon electrodes (GCE) covered with mesoporous silica films prepared by EASA at increasing synthesis times, respectively before (Fig. 1A) and after surfactant extraction (Fig. 1B). This cationic redox probe has been selected as this is the only one likely to distinguish the coating uniformity (neutral probes can dissolve in the surfactant phase and negative probes suffer from restricted diffusion through the film [35]). Part $\mathrm{C}$ of the figure represents the relative variations of peak current differences between bare and modified electrodes as a function of film deposition time. Prior to template removal, and as far as thin films are produced as uniform deposits over the whole electrode surface area, no signal for the redox probe is expected to be seen [11a,12a,25]. Fig. 1A shows that it is indeed the case for the films obtained after sufficient synthesis time ( $>16 \mathrm{~s})$ whereas significant defects or incomplete electrode coverage was observed for deposition times shorter than $12 \mathrm{~s}$ (see black curve on Fig. 1C). After template removal, all modified electrodes gave rise to significant response of the probe (Fig. 1B), even for the films covering uniformly the electrode surface thanks to their open mesoporosity, yet with some decrease in intensity for the much thicker deposits (see red curve on Fig. 1C) which can be explained by increased resistance to mass transport through the film. The presence of particles/aggregates over thicker films, i.e., those formed at longer deposition times, as previously reported [11a,14] and confirmed by scanning electron microscopy (Fig. SI 1), might also contribute to explain slower transport rates.

Figure 1

Profilometry measurements were then carried out to estimate film thicknesses (Table 1). Due to the important roughness of the GCE surface, thinner films were not analysable by the technique (wellknown limitation [36]), but other data gave rise to a variation expected from previous studies, with thickness values in the sub-micrometric range, increasing with the deposition time, and characterized by high dispersion for the thicker ones as a result of the presence of particles/aggregates [14]. To confirm the observed trend, similar series of experiments have been performed with films deposited on ITO (flatter than GCE) and comparable variations were observed in both cases (Table 1). Note that the absence of exploitable profilometry signal for deposits generated at short synthesis time can also be due to incomplete coverage of the electrode surface, in agreement with permeability data obtained by cyclic voltammetry, as discussed above (Fig. 1). 
Table 1. Film thicknesses measured by stylus profilometry for samples deposited galvanostatically (current density $=3.71 \times 10^{-4} \mathrm{~A} \mathrm{~cm}^{-2}$ ) on glassy carbon electrode (GCE) and (for comparison) potentiostatically $($ potential $=-1.3 \mathrm{~V}$ ) on indium-tin oxide $($ ITO) electrode, by EASA for increasing deposition times.

\begin{tabular}{cclccc}
\hline & \multicolumn{3}{c}{ GCE } & \multicolumn{3}{c}{ ITO } \\
\hline $\begin{array}{c}\text { Dep. time } \\
(\mathrm{s})\end{array}$ & $\begin{array}{c}\text { Dep. charge }[\mathrm{a}] \\
\left(\mu \mathrm{C} \mathrm{cm}^{-2}\right)\end{array}$ & $\begin{array}{l}\text { Thickness } \\
(\mathrm{nm})\end{array}$ & $\begin{array}{c}\text { Dep. time } \\
(\mathrm{s})\end{array}$ & $\begin{array}{c}\text { Dep. charge [a] } \\
\left(\mu \mathrm{cm}^{-2}\right)\end{array}$ & $\begin{array}{l}\text { Thickness } \\
(\mathrm{nm})\end{array}$ \\
\hline 5 & 1.83 & n.m. [b] & 5 & 1.55 & n.m. [b] \\
8 & 2.96 & n.m. [b] & 8 & 2.38 & n.m. [b] \\
10 & 3.70 & n.m. [b] & 10 & 3.01 & $15 \pm 3$ \\
12 & 4.43 & $74 \pm 5$ & 12 & 3.94 & $46 \pm 10$ \\
16 & 5.92 & $119 \pm 13$ & 16 & 4.72 & $58 \pm 7$ \\
20 & 7.38 & $268 \pm 160$ & 20 & 6.30 & $264 \pm 120$ \\
30 & 11.1 & $384 \pm 200$ & 30 & 8.35 & $318 \pm 170$ \\
\hline
\end{tabular}

[a] for comparison purposes, as films have been prepared differently on GCE and ITO (respectively by galvanostatic and potentiostatic EASA), and deposition charges (Dep. charge) are given as charge densities (i.e., divided by the electrode surface area). [b] non measurable.

The film modified electrodes were then used to discuss the influence of deposition time on paraquat detection by square wave voltammetry (SWV). Typical results are depicted on Figure 2 for various paraquat concentrations in the $\mu \mathrm{M}$ range. No noticeable difference can be seen when passing from bare GCE to a film generated for 5 s (compare parts A1 \& A2 of Fig. 2), suggesting that no (or very little) silica has been deposited. Then, the films prepared at longer deposition times led to proportional increases in sensitivity (see illustrative raw data in parts A3 \& A4 and calibration curves in part B of Fig. 2). This confirms the accumulation ability of the mesoporous silica film towards cationic paraquat species and indicates most effective accumulation behavior when increasing the film thickness (due to more available binding sites, i.e., silanolate groups, onto the electrode surface). In parallel, a negative shift in peak potentials (by $c a .100 \mathrm{mV}$ with respect to the bare GCE) was observed, as a consequence of the interactions between the analyte and the film. The optimum sensitivity $\left(2.1 \mathrm{~A} \mathrm{~cm}^{-2} \mathrm{M}^{-1}\right.$ ) was obtained for the film deposited for $16 \mathrm{~s}$ (corresponding to ca. $120 \mathrm{~nm}$ thickness), as determined from calibration curve in the 0.5 to $10 \mu \mathrm{M}$ concentration range (Fig. 2B). In this case, a preconcentration factor of almost 30 can be achieved with respect to bare ITO. For thicker films, however, a gap to the ideal linear variation was observed, the 
calibration curves becoming S-shaped (Fig. 2B). A possible explanation for lower response than expected at low paraquat concentration when using thicker films is that the few quantity of accumulated paraquat is mostly located in the upper part of the film (i.e., close to the solution side where preconcentration in the film started to occur) and thus less available to be detected at the electrode surface. An additional observation supporting this hypothesis is the fact that this limiting effect was more pronounced with the thickest film (compare the responses of films $20 \& 30 \mathrm{~s}$ in Fig. 2B). At larger analyte concentrations, the electrode response became again more or less linear but rapidly tended to level off. Such a behavior can be explained by stronger resistance to mass transport through thicker films (slower diffusion rates), as also supported by permeability measurements discussed above (see red curve in Fig. 1C). Note that thick films contain indeed a large amount of binding sites (as ascertained by peak current increase when performing multiple cyclic voltammetric scans, see Fig. 3), but they cannot be exploited for single SWV measurements. From these cyclic voltammetry data, one can also confirm the strong interactions between paraquat and the mesoporous silica film (progressive shift of peak potentials towards more negative values) and the real accumulation of the probe into the film (decrease in peak potential difference from 60 $\mathrm{mV}$ for the first scan to $\mathrm{ca} .40 \mathrm{mV}$ for the $40^{\text {th }}$ scan, due to progressive shift of diffusion-controlled processes to thin layer behavior). These results indicates that when performing preconcentration electroanalysis with porous film electrodes, a compromise has to be found for getting the optimal sensitivity: the film should be thick enough to offer a high number of accumulation sites, but not too thick to avoid limitations for trace analysis (analyte binding far away from the sensing electrode surface) and a levelling off in the modified electrode response (due to restricted mass transport through thick films). From the sensor point of view, since the recognition/preconcentration is based just on the binding of cationic species to the negatively charged silica surface, the selectivity of this approach in view of practical applicability in samples where other cations may coexist can be questionable but we have shown in a previous work that analysis of real water samples (i.e., river water) by the standard addition method is indeed possible [21]. The electrodes can be used for more than 20 successive measurements on the same day without cleaning but suffer from poor long-term stability beyond that period due to the well-known degradation of silica gel materials over prolonged use in aqueous media. Good reproducibility values were found for both intra-electrode $(99.1 \%, n=9)$ and inter-electrode $(95.3 \%, n=3)$ measurements.

Figure 2

Figure 3 
In order to further confirm this behavior, we have performed additional experiments using the optimal $16 \mathrm{~s}$ film, but in the form of monolayer, bilayer and trilayer configurations (it is indeed possible to get multi-layered mesoporous silica films by EASA [37]). The results (Fig. SI 2A) indicate that almost no improvement can be obtained when passing from the mono- to the bilayer film, showing the same type of limitations as discussed above, and the situation was even worse with the trilayer film, suffering from stronger diffusional restrictions. Again, the limitation in the SWV was of kinetic kind, as multisweep cyclic voltammetry revealed that the number of binding sites was indeed increased when passing from the mono- to the bi- and trilayer films (see the $100^{\text {th }}$ cycles obtained for these three films in Fig. SI 2B).

In summary, the above results indicate clearly that increasing the thickness of mesoporous silica films resulted in significant increase in the number of binding sites present at the electrode surface, which can indeed contribute to dramatically increase its sensitivity when applied to preconcentration electroanalysis, but too thick films have to be avoided because they induce mass transport restrictions (accumulation too far from the sensing electrode surface in case of trace analysis, or signal levelling off effects).

\section{Experimental}

The origin and purity of chemicals used here, as well as the apparatus characteristics, have been detailed in Supporting Information. Glassy carbon plates (SIGRADUR G, $20 \mathrm{~mm} \times 10 \mathrm{~mm} \times 1$ $\mathrm{mm})$ were purchased from HTW Germany. These plates were polished and cleaned using $(3,1$ and $0.05 \mu \mathrm{m}$ ) alumina particles at polishing cloth followed by 5 minutes sonication with ultrapure water. The mesoporous silica films were prepared by electrochemically assisted self-assembly on APTESelectrografted glassy carbon electrodes (GCE), by adapting a previously described method [16]. APTES $\left(1 \mathrm{mM}\right.$ in $0.1 \mathrm{M} \mathrm{Bu}_{4} \mathrm{NBF}_{4}$ in acetonitrile) was grafted on cleaned GCE $\left(\mathrm{A}=3.4 \mathrm{~cm}^{2}\right)$ by single CV scan (between +0.7 and $+2.0 \mathrm{~V}$ at a rate of $100 \mathrm{mV} \mathrm{s}^{-1}$ ), which was then rinsed abundantly with acetone. Typical sol for silica films deposition was prepared by using ethanol and $0.1 \mathrm{M}$ aqueous $\mathrm{NaNO}_{3}$ in $1 / 1 \mathrm{v} / \mathrm{v}$ ratio to which TEOS $(100 \mathrm{mM})$ and CTAB $(32 \mathrm{mM})$ were added and $\mathrm{pH}$ was adjusted to 3 with $\mathrm{HCl}$. The sol was stirred for 2.5 hours for proper hydrolysis of TEOS. A portion of the electrode area $\left(\mathrm{A}=0.5 \mathrm{~cm}^{2}\right)$ was contacted to the sol and film formation was achieved under galvanostatic conditions by applying a current density, $j$, of $-0.74 \mathrm{~mA} \mathrm{~cm}{ }^{-2}$ (optimized value [14]). Silica films were grown for various deposition times: 5, 8, 10, 12, 16, 20, and $30 \mathrm{~s}$ for monolayer films. Multilayered films were also deposited by EASA process (typically for $16 \mathrm{~s}$ repeated two or three times to get either bilayer or trilayer films), as previously described [37]. All mesoporous silica modified electrodes were treated overnight at $130{ }^{\circ} \mathrm{C}$, and the surfactant 
template was extracted using $0.1 \mathrm{M} \mathrm{HCl}$ in ethanol under moderate stirring for 15 min to $1 \mathrm{~h}$ depending upon film deposition time (IR spectroscopy was used to check the time required for complete extraction).

\section{Acknowledgements}

This work was supported in part by the French Programme Investissement d'Avenir (PIA) "Lorraine Université d'Excellence" (Reference No. ANR-15-IDEX-04-LUE). T. N. is grateful to the Higher Education Commission of Pakistan for funding his Ph.D. N. A. V. thanks the French Embassy in Ukraine for a mobility financial help through the "Campus France" program. The authors are also thankful to Dr. Liang Liu for help in profilometry measurements.

\section{References}

[1] D. Jyoti, D. Mohan, A. Singh, D. S. Ahlawat, Mater. Sci. Forum 2014, 771, 53-69.

[2] a) I. E. Rauda, V. Augustyn, B. Dunn, S. H. Tolbert, Acc. Chem. Res. 2013, 46, 1113-1124; b) A. Patil, V. Patil, J.-W. Choi, J.-S. Kim, S.-J. Yoon, J. Nanosci. Nanotechnol. 2017, 17, 2971.

[3] E. L.Runnerstrom, A. Llordes, S. D. Lounis, D. J. Milliron, Chem. Commun. 2014, 50, 1055510572.

[4] M. Matsuoka, T. Toyao, Y. Horiuchi, M. Takeuchi, M. Anpo in Photocatalysis and Water Purification (Ed. P. Pichat), Wiley-VCH Verlag GmbH \& Co. KGaA, Weinheim, 2013, pp. 179-197.

[5] T. Hyodo, Chem. Sensors 2010, 26, 62-72.

[6] A. Walcarius, Chem. Soc. Rev. 2013, 42, 4098-4140.

[7] a) A. Walcarius, Electroanalysis 2015, 27, 1303-1340; b) M. Etienne, L. Zhang, N. Vilà, A. Walcarius, Electroanalysis 2015, 27, 2028-2054.

[8] C. Sanchez, C. Boissiere, D. Grosso, C. Laberty, L. Nicole, Chem. Mater. 2008, 20, 682-737.

[9] Y. Yamauchi, N. Suzuki, L. Radhakrishnan, L. Wang, Chem. Rec. 2009, 9, 321-339.

[10] U-H. Lee, M.-H. Kim, Y.-U. Kwon, Bull. Kor. Chem. Soc. 2006, 27, 808-816.

[11] a) A. Walcarius, E. Sibottier, M. Etienne, J. Ghanbaja, Nature Mater. 2007, 6, 602-608; b) Z. Teng, G. Zheng, Y. Dou, W. Li, C. Y. Mou, X. Zhang, A. M. Asiri, D. Zhao, Angew. Chem. Int. Ed. 2012, 51, 2173-2177; c) K.-C. Kao, C.-H. Lin, T.-Y. Chen, Y.-H. Liu, C.-Y. Mou, J. Am. Chem. Soc. 2015, 137, 3779-3782.

[12] a) F. Yan, X. Lin, B. Su, Analyst 2016, 141, 3482-3495; b) A. Walcarius, Curr. Opin. Electrochem. 2018, in press (DOI: 10.1016/j.coelec.2018.03.017). 
[13] M. Etienne, Y. Guillemin, D. Grosso, A. Walcarius, Anal. Bioanal. Chem. 2013, 405, 14971512.

[14] A. Goux, M. Etienne, E. Aubert, C. Lecomte, J. Ghanbaja, A. Walcarius, Chem. Mater. 2009, 21, 731-741.

[15] C. Robertson, R. Beanland, S. A. Boden, A. L. Hector, R. J. Kashtiban, J. Sloan, D. C. Smith, A. Walcarius, Phys. Chem. Chem. Phys. 2015, 17, 4763-4770.

[16] T. Nasir, L. Zhang, N. Vilà, G. Herzog, A. Walcarius, Langmuir 2016, 32, 4323-4332.

[17] a) Q. Sun, F. Yan, L. Yao, B. Su, Anal. Chem. 2016, 88, 8364-8368; b) W. Zheng, F. Yan, B. Su, J. Electroanal. Chem 2016, 781, 383-388.

[18] a) L. Yao, F. Yan, B. Su, Analyst 2016, 141, 233-237; b) F. Yan, Y. He, L. Ding, B. Su, Anal. Chem. 2015, 87, 4436-4441.

[19] F. Yan, W. Zheng, L. Yao, B. Su, Chem. Commun. 2015, 51, 17736-17739.

[20] Y. He, L. Ding, B. Su, Sci. China Chem. 2015, 58, 1593-1599.

[21] T. Nasir, G. Herzog, L. Liu, M. Hébrant, C. Despas , A. Walcarius, ACS Sensors 2018, 3, 484-493.

[22] Q. H. Wang, W. Z. Li, B. Su, J. Zhejiang Univ. (Sci. Ed.) 2015, 42, 440-444.

[23] F. Yan, B. Su, Anal. Chem. 2016, 88, 11001-11006.

[24] X. Lin, Q. Yang, F. Yan, B. Zhang, B. Su, ACS Appl. Mater. Interfaces 2016, 8, $33343-$ 33349.

[25] N. Vilà, E. André, R. Ciganda, J. Ruiz, D. Astruc, A. Walcarius, Chem. Mater. 2016, 28, 2511-2514.

[26] M. B. Serrano, C. Despas, G. Herzog, A. Walcarius, Electrochem. Commun. 2015, 52, 34-36.

[27] a) N. Vilà, J. Ghanbaja, E. Aubert, A. Walcarius, Angew. Chem. Int. Ed. 2014, 53, 2945-2950;

b) N. Vilà, J. Ghanbaja, A. Walcarius, Adv. Mater. Interfaces 2016, 3, 1500440.

[28] a) M. Etienne, A. Goux, E. Sibottier, A. Walcarius, J. Nanosci. Nanotechnol. 2009, 9, 23982406; b) G. Herzog, N. A. Vodolazkaya, A. Walcarius, Electroanalysis 2013, 25, 2595-2603.

[29] W. Li, L. Ding, Q. Wang, B. Su, Analyst 2014, 139, 3926-3931.

[30] a) I. Fernández, A. Sánchez, P. Díez, P. Martínez-Ruiz, P. Di Pierro, R. Porta, R. Villalonga, J. M. Pingarrón, Chem. Commun. 2014, 50, 13356-13358; b) M. Saadaoui, I. Fernández, A. Sánchez, P. Díez, S. Campuzano, N. Raouafi, J. M. Pingarrón, R. Villalonga, Electrochem. Commun. 2015, 58, 57-61; c) M. Saadaoui, I. Fernández, G. Luna, P. Diez, S. Campuzano, N. Raouafi, A. Sánchez, J. M. Pingarrón, R. Villalonga, Anal. Bioanal. Chem. 2016, 408, 7321 7327; d) W. Argoubi, A. Sánchez, C. Parrado, N. Raouafi, R. Villalonga, Sensors Actuat. B 2018, 255, 309-315. 
[31] a) M. Rafiee, B. Karimi, S. Arshi, H. Vali, Dalton Trans. 2014, 43, 4901-4908; b) L. Ding, W. Li, Q. Sun, Y. He, B. Su, Chem. Eur. J. 2014, 20, 12777-12780.

[32] Z. Zhou, W. Guo, L. Xu, Q. Yang, B. Su, Anal. Chim. Acta 2015, 886, 48-55; b) W. Guo, X. Lin, F. Yan, B. Su, ChemElectroChem 2016, 3, 480-486.

[33] J. Liu, D. He, Q. Liu, X. He, K. Wang, X. Yang, J. Shangguan, J. Tang, Y. Mao Anal. Chem. 2016, $88,11707-11713$.

[34] a) Q. Yang, X. Y. Lin, B. Su, Anal. Chem. 2016, 88, 10252-10258; b) X. Y. Lin, Q. Yang, F. Yan, B. W. Zhang, B. Su, Anal. Chem. 2016, 88, 7821-7827; c) W. H. Wu, Q. Yang, B. Su, J. Membr. Sci. 2018, 558, 86-93.

[35] C. Karman, N. Vilà, A. Walcarius, ChemElectroChem 2016, 3, 2130-2137.

[36] A. Piegari, E. Masetti, Thin Solid Films 1985, 124, 249-257.

[37] G. Giordano, N. Vilà, E. Aubert, J. Ghanbaja, A. Walcarius, Electrochim. Acta 2017, 237, 227-236. 
Figure captions

Figure 1. (A,B) Cyclic voltammograms recorded in $0.5 \mathrm{mM} \mathrm{Ru}\left(\mathrm{NH}_{3}\right)_{6} \mathrm{Cl}_{3}$ (in $0.1 \mathrm{M} \mathrm{KCl}$ ) using GCE electrodes modified with mesoporous silica films generated by EASA for various times, respectively before (A) and after surfactant removal (B). (C) Relative ratios of peak current intensities obtained at film electrodes with respect to bare GCE, as expressed as a function of film deposition time. Potential scan rate: $100 \mathrm{mV} \mathrm{s}^{-1}$.

Figure 2. (A) Square wave voltammograms (SWV) recorded in $0.5,2,3.5,5,6.5,8$ and $10 \mu \mathrm{M}$ paraquat (in $0.07 \mathrm{M} \mathrm{NaNO}_{3}, \mathrm{pH}$ 6) using GCE electrodes modified with mesoporous silica films generated by EASA for $0 \mathrm{~s}$ (bare GCE, $\left.\mathrm{A}_{1}\right), 5 \mathrm{~s}\left(\mathrm{~A}_{2}\right), 10 \mathrm{~s}\left(\mathrm{~A}_{3}\right)$ and $16 \mathrm{~s}\left(\mathrm{~A}_{4}\right)$. (B) Corresponding calibration curves, including also additional data obtained with other film electrodes.

Figure 3. Multisweep cyclic voltammograms (40 first scans) recorded in $5 \mu \mathrm{M}$ paraquat (in $0.07 \mathrm{M}$ $\mathrm{NaNO}_{3}, \mathrm{pH}$ 6) using a GCE electrode modified with a mesoporous silica film generated by EASA for $30 \mathrm{~s}$. Potential scan rate: $20 \mathrm{mV} \mathrm{s}^{-1}$. 